IP Periodica Polytechnica

Transportation Engineering

47(3), pp. 251-256, 2019

https://doi.org/10.3311/PPtr.12112

Creative Commons Attribution (i)

RESEARCH ARTICLE

\section{On the Concentration and Phase-relation Dependence of Seebeck Coefficient and the Contact Angle in Metallic Solutions}

\author{
Attila Szabo ${ }^{1,2, *}$, Akos Hambalgo ${ }^{1}$, Gergo Megyer ${ }^{1}$, Antal Lovas ${ }^{1}$
}

Received 28 August 2017; accepted 19 February 2018

\begin{abstract}
The focus of this paper is the deeper understanding of the effect of the change in the electronic structure on the wetting angle and transport properties. For this purpose, using the alloys from the earlier study, the thermopower has been measured and the Seebeck coefficient has also been determined in room temperature (solidified state). During the experiments in both case the modification of the electronic structure were performed by alloying on a way, that the investigated systems are terminal $(\alpha)$ solutions in solid state. The concentration dependence of property changes are interpreted on the bases of free electron model elaborated earlier for this alloy types. This prediction fits well also to the concentration dependence of heat of formation in these alloys. Similar concentration dependence has been also found between the Seebeck coefficient, the resistivity and the heat of mixing in $\alpha$-phase Fe-Ni alloys. The shift of thermopower were also monitored in order to detect the crystallization (first oreder transformation) starting form amorphous $\mathrm{Fe}-\mathrm{B}$ alloys.
\end{abstract}

\section{Keywords}

thermopower, heat of mixing, resistivity, wetting

\footnotetext{
${ }^{1}$ Department of Automotive Technologies,

Faculty of Transportation Engineering and Vehicle Engineering,

Budapest University of Technology and Economics,

H-1521 Budapest, P.O.B. 91, Hungary

${ }^{2}$ Department of Mechanical Engineering,

Faculty of Electrical Engineering and Informatics,

University of Dunaujvaros,

H-2400, Dunaujvaros, Tancsics M. u. 1/a, Hungary

* Corresponding author, e-mail: szaboattila@uniduna.hu
}

\section{Introduction}

Thermopower (U) - measured between two contacting solid metallic phases - and the wetting phenomenon observed between solid and liquid phases (characterized by the contact angle $(\Theta)$ ), are basic phenomena in technical testing of the engineering metallic materials. In spite of their technical simplicity, these measurements are rarely applied as material testing (Szabó et al., 2012). The reason is the complicate interpretation of experimental results associated with the multicomponent nature of technical alloys.

Originally, both phenomena are the consequence of the evolution of direct physical contacts between single component solid-solid or solid liquid phases.

The Seebeck coefficient (S) defined according to the Mott's approximation (Mott, 1993):

$$
S_{d}(T)=\frac{\pi^{2}}{3} \cdot \frac{k_{B}{ }^{2} \cdot T}{e} \cdot\left(\frac{\partial \ln \sigma(\varepsilon)}{\partial \varepsilon}\right)_{\varepsilon=\varepsilon_{f}}
$$

(where $\sigma(\varepsilon)$ is the energy dependent conductivity, $\mathrm{k}_{\mathrm{b}}$ is the Bolzmann constant, e is the charge of an electron and $\varepsilon$ is the kinetic energy of the free electron).

The wettability between single component solid and liquid phases, which is commonly expressed by the Young equation (Kaptay, 2005):

$$
\cos \theta=\frac{\left(\gamma_{s v}-\pi_{s g}\right)-\gamma_{s l}}{\gamma_{\mathrm{lg}}}=\frac{\gamma_{s g}-\gamma_{s l}}{\gamma_{\mathrm{lg}}}
$$

where $\gamma_{\mathrm{sg}}$ is the solid-vapor interfacial energy, $\gamma_{\mathrm{sl}}$ is the solidliquid interfacial energy, $\gamma_{\mathrm{lg}}$ is the liquid-vapor interfacial energy and $\theta$ is the equilibrium contact angle.

In this paper, the role of alloying effects on these phenomena will be discussed.

The compositional changes restrict to host metal replacement within the same phases, i.e. within the limit of $\alpha$-solid solubility consequently the investigated alloys are single phase in their solidified state.

The free electron model (Weltsch et al., 2011) used for the interpretation of experimental results. 


\section{Experimental}

The following alloys are investigated in the experiments:

- Ag-Sn and Ag-Sb solid solutions ("electron phases") to measure the concentration dependence of Seebeck coefficient.

- Single phase Fe-Ni solid solutions (below $10 \mathrm{at} \% \mathrm{Ni}$ ) to measure the thermopower change in solid state, comparing them with the concentration dependence of heat of mixing during the formation of these alloys.

\section{Results and discussion}

\subsection{Relation between the change in valence} electron concentration and the thermopower in the solidified alloys

The concept of "electron phases" represents the simplest method for describing of driving force $\left(\Delta \mathrm{G}_{\mathrm{A}}=\Delta \mathrm{H}_{\text {mix }}-\mathrm{T} \Delta \mathrm{S}_{\text {mix }}\right)$ of alloy formation.

Here, $\Delta \mathrm{G}_{\mathrm{A}}$ is the total free energy change of alloy formation, $\Delta \mathrm{H}_{\text {mix }}$ and $\Delta \mathrm{S}_{\text {mix }}$ are the heat of mixing and the mixing entropy change respectively.

Note, that during the liquid state mixing, the term $\Delta \mathrm{S}_{\text {mix }} \sim 0$, consequently, the free enthalpy change can be characterized by the heat of mixing.

Several alloys assigned by " $\alpha$ - solid solutions" belong to this alloy category, mainly those, in which both components (solvent and solutes) exhibit typical metallic character (small electron negativity according to the Pauling scale) (Hlinka and Weltsch, 2013; Salacz and Weltsch, 2013). In this respects, typical examples are the Ag-based liquids and the solid solutions formed during the solidification of these liquids.

The role of bulk electron concentration on the surface tension in Ag-based liquids (Weltsch et al., 2011) and the Seebeck coefficient (defined by the Eq. (2)) in Ag-based solids are investigated. The alloy formation between such components often exhibit extended " $\alpha$-solubility" in solid state. In the investigated Fe-Ni solid solutions within the $\alpha$-solubility region, the $\mathrm{d}$-electron-concentration is altered when replacing partially the Fe-host metal with $\mathrm{Ni}$ atoms.

The measuring data of such alloy examples are illustrated related to Ag-Sn and Ag-Sb solid solutions - on Fig. 1-4, and - related to Fe-Ni diluted solid solutions - on Fig. 7-8.

On Fig. 1, and Fig. 3, the change of wetting angle for $\mathrm{AgSn}_{3}, \mathrm{AgSn}_{5}$ and $\mathrm{AgSb}_{3}, \mathrm{AgSb}_{5}$ melts are plotted - measured on graphite substrate - versus the melt temperature. Both of alloys are solid solution in solidified state (identical crystal structure, but varying valence electron concentration, defined as valence electron per atom, e/a). One can see that wetting angle increases with increasing solute content (increasing e/a concentration). Simultaneously, the Seebeck coefficient (measured at room temperature) slightly shifts, with higher solute content (see Fig. 2).

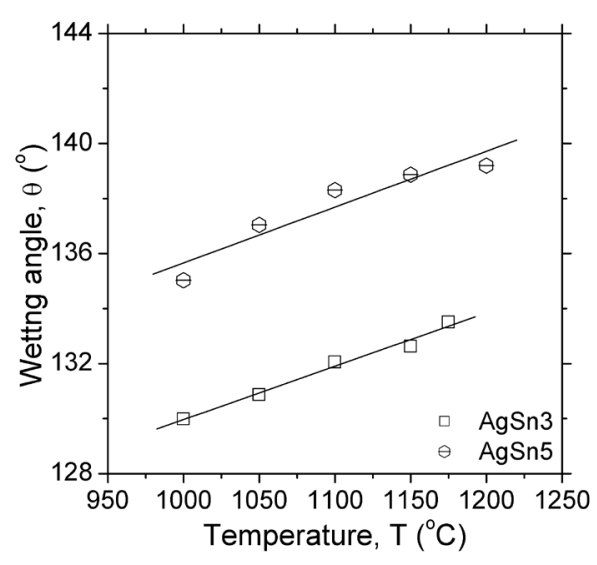

Fig. 1 Temperature dependence of wetting angle $(\theta)$ of $\mathrm{AgSn}_{3}$ and $\mathrm{AgSn}_{5}$ melt on graphite substrate (Weltsch et al., 2011)

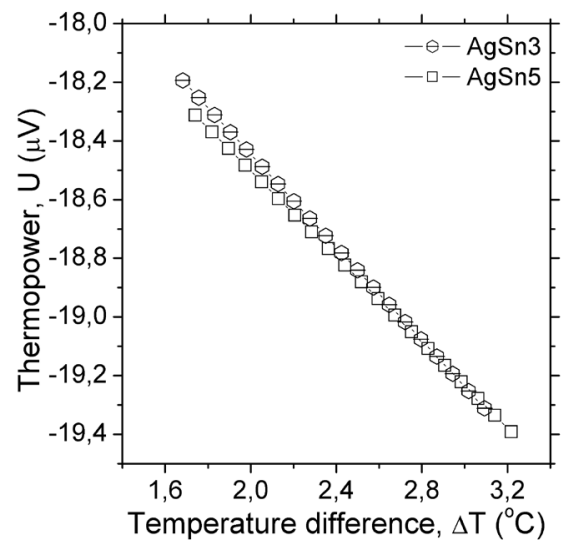

Fig. 2 The thermopower of $\mathrm{AgSn}_{3}$ and $\mathrm{AgSn}_{5}$ alloys versus the temperature difference $(\Delta \mathrm{T})$

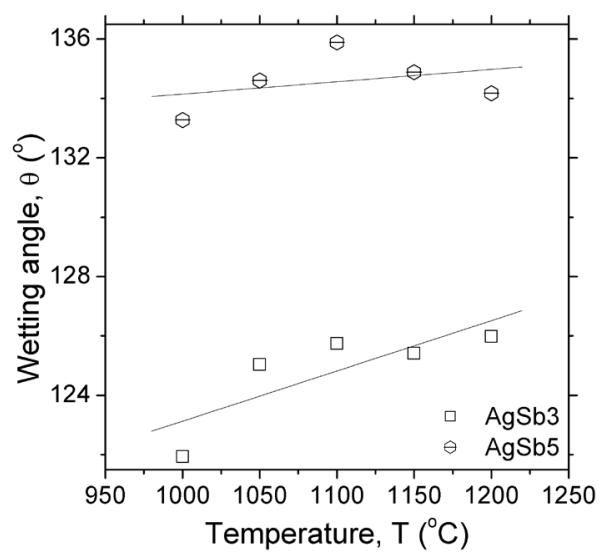

Fig. 3 Temperature dependence of wetting angle $(\theta)$ of $\mathrm{AgSb}_{3}$ and $\mathrm{AgSb}_{5}$ melt on graphite substrate (Weltsch et al., 2011)

The tendency can be explained by the free electron model calculation applied to the electron structure description in these alloys (see in Weltsch et al. (2011)): 


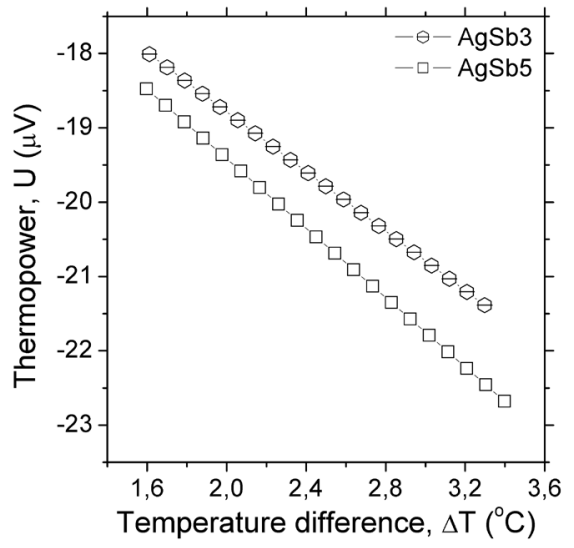

Fig. 4 The thermopower of $\mathrm{AgSb}_{3}$ and $\mathrm{AgSb}_{5}$ solid solutions versus the temperature difference $(\Delta \mathrm{T})$

$$
\gamma=\frac{\hbar^{2}}{m} \cdot \frac{1}{32 \pi}(3 \pi n)^{\frac{4}{3}}
$$

According to the Eq. (3), the surface energy of the melt $(\gamma)$ (which represents the cohesive energy in the melt drop) changes near linearly with the number of conduction electrons (n).

This increase is consistent with the change of the wetting angle between the melt drop on the inert graphite substrate. This tendency is also supported by the -experimentally determined- concentration dependence of heat of mixing in the $\mathrm{Ag}-\mathrm{Sn}$ and in $\mathrm{Ag}-\mathrm{Sb}$ system, as on Fig. 5 and 6 are illustrated.

Such rapid increase of mixing enthalpy is also typical in the terminal region of solute formation (low concentration range, in which each solute atoms are preferentially coordinated with the solvent, host metal atoms).

One can expect therefore, that cohesion in the melt, together with the surface energy of the liquid drop tends to increase also, while the contact interaction between the melt and the inert substrate remains constant. Hence, the melt drop tends to exhibit more perfect spherical shape, i.e. the wetting angle $(\Theta)$ increases.

One can see, that correlation exists between the concentration dependence of heat of mixing and the thermopower change (measured in the appropriated solid state) as well as the direction of wetting angle change in Ag-based diluted solutions (measured on graphite substrate). Similar correlation was found in Fe-Ni system, as the Fig. 7 and 8 shows.

According to Fig. 7, the $\mathrm{S}$ shifts rapidly into the negative direction within the region of $\alpha$-solid solutions, as the $\mathrm{Ni}$ content increases. This change is consistent with the Mott's approximation (Eq. (1)), which predicts of the rapid change of electrical conductivity in the terminal concentration, due to the increasing bonding strength between the electrons in the valence band, near the vicinity of Fermi surface. Accordingly, the heat of mixing increases drastically within this concentration range. (See Fig. 8.)

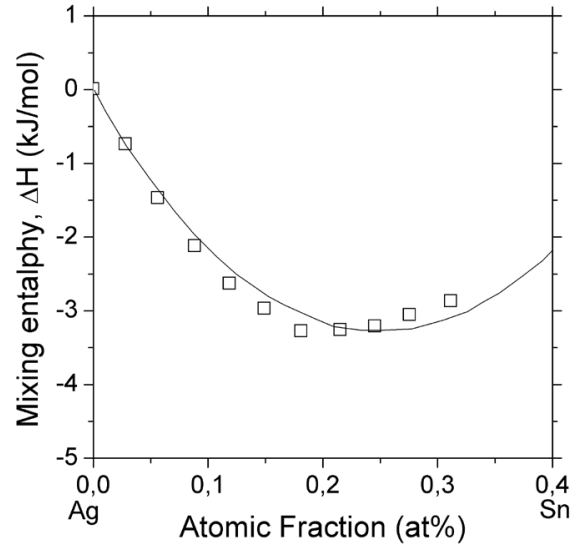

Fig. 5 The change of mixing enthalpy in Ag-Sn alloys versus the concentration (Hultgren et al., 1973)

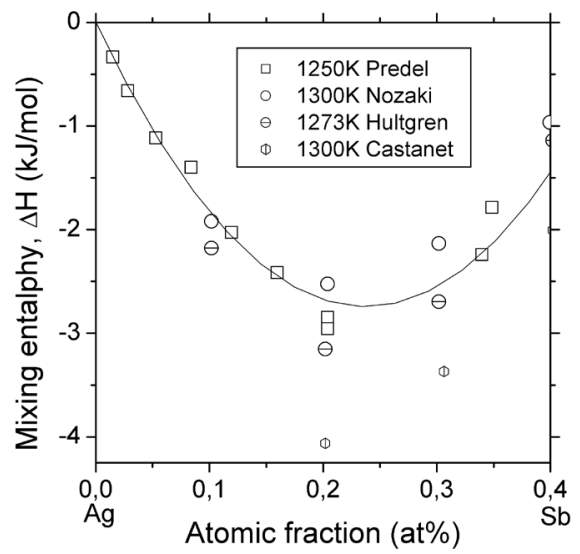

Fig. 6 The change of mixing enthalpy in Ag-Sb alloys versus the concentration (Hultgren et al., 1973)

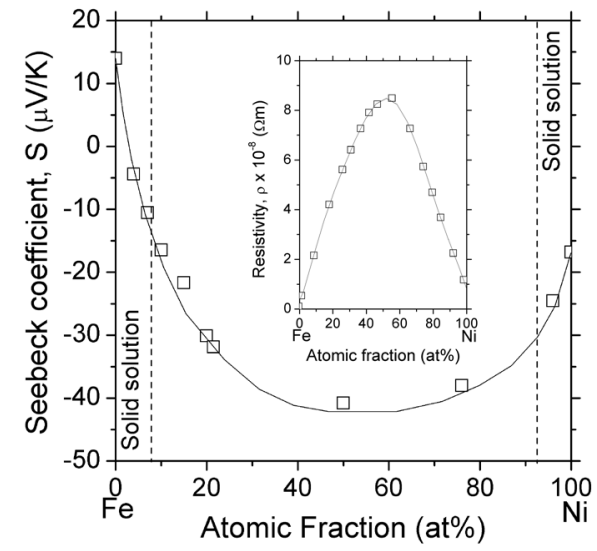

Fig. 7 The concentration dependence of Seebeck coefficient in Fe-Ni system (insert: Resistivity vs. the Ni content (Ho et al., 1983))

\subsection{The chemical character of components and the shift of Seebeck coefficient}

In Szabo and Lovas (2009), some basic observations are outlined on the factors, which influence the magnitude and sign 


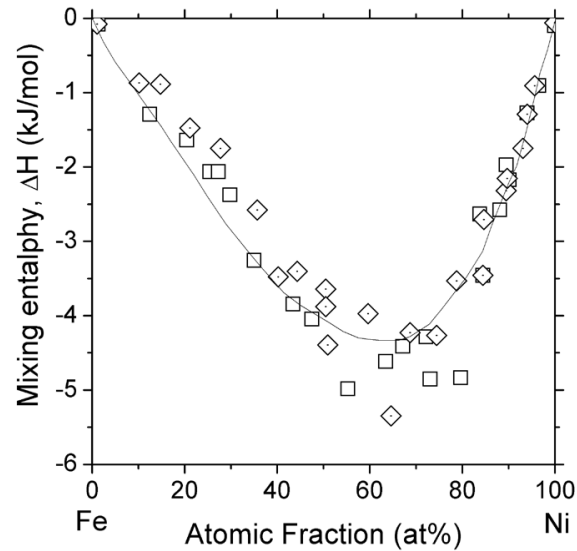

Fig. 8 The change of mixing enthalpy in Fe-Ni alloys versus the concentration (Swartzendruber et al., 1991)

of Seebeck coefficient between various metallic elements and the $\mathrm{Cu}$ electrode, used during our measurements. It was concluded, that analogy exists between the magnitude and sign of the thermoelectric power which is developed between various metal and $\mathrm{Cu}$ electrode (used in our measurements) and the electrochemical normal potential of different metallic elements compared with the reference H-electrode. Hence, the sign of thermopower can be positive and negative.

The magnitude of the $\mathrm{S}$ depends on the relation between the Fermi energy (which is characteristic for the stable phase at the given temperature) and the population density of valency electrons around this energy.

As it was shown in the previous examples, if the concentration of the dissolved foreign atoms is changed, then the electron density (around the Fermi level) is also modified i.e. altered without the change of the single phase nature of the host metal (electron structure change within the solubility limit). In this case, the chemical and physical properties of the alloy gradually change. The illustrated properties, like $\mathrm{S}$ in solid state and the cohesive energy in the appropriate alloy in liquid state also continuously change as it is visible in the Figs. 7 and 8. Nevertheless, the global electron-electron interaction, i.e. the free-electron character of valence electrons is only slightly affected.

Another group of the investigated alloys are also single phase, but the long-range crystal-periodicity is absent (glassy alloys). The absence of crystal periodicity is the consequence of rapid cooling of the appropriate liquids.

The components strongly differ from those treated in the previous alloys.

Two strongly different component character can be distinguished in the (glassy) alloys:

1. Metalloids, with relative high electronegativity (B and $\mathrm{Si}$ ). The bonding between the metalloids and the neighbouring metal atoms is partially covalent in (equilibrium) crystalline state. Accordingly, in the amorphous (disordered) state weak electron localization is developed, resulting considerable electrical resistance increases (Gulyas and Lovas, 2004).

2. The matrix atoms are $3 \mathrm{~d}$-transition metals. The main feature of electronic structure in these metallic elements is the partially filled d-electron band. In the case of Fe, the valence band electron configuration is: (3d)6(4s) 2 and for $\mathrm{Ni}(3 \mathrm{~d}) 8(4 \mathrm{~s}) 2$. If the metallic host consists from single TM element then single local bonding type is developed between the M and TM atoms only. However, the local hidden symmetry of metallic allotrope may also has impact on several properties, like the transport properties or the magnitude of enthalpy trapping (Lovas et al., 1995).

\subsection{The influence of chemical character and concentration of metalloids on the Seebeck coefficient}

The influence of B and Si content (two metalloid type) on the change of Seebeck coefficient were investigated and the results are illustrated in Figs. 9 and 10. Here the $S$ is illustrated as the function of the metalloid content. The common is, that $S$ decreases only slightly with increasing metalloid concentration. The change is monotonic between 14-25 at\% B content. In contrast, a plateau appears, when the B is gradually replaced by $\mathrm{Si}$, which hints to the existence of a hidden structural change (hidden phase reminiscence, i.e. the Si does stabilize the fcc environment, while B doesn't show any phase selection.) The global effect of metalloids is manifested in the hindering of electron mobility. As the electron mobility decreases (increasing average bonding state), this may be manifest in the net decreasing valence electron density of state in the vicinity Fermi level.

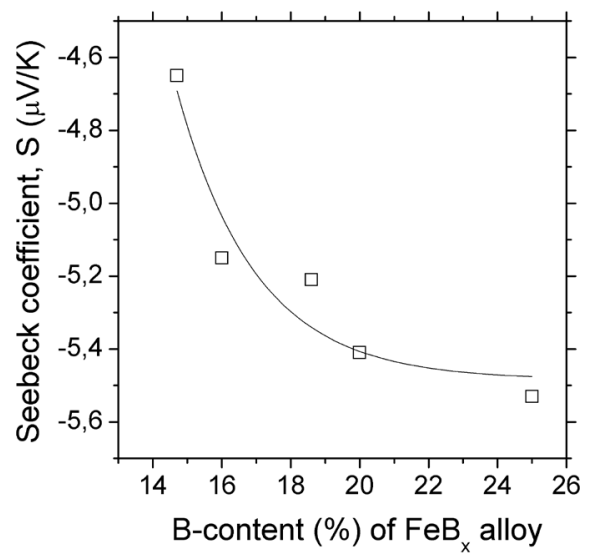

Fig. 9 The dependence of S on the boron content in binary Fe-B glasses

\subsection{Host metal replacement with $\mathrm{Ni}$}

As it was discussed before (Figs. 7 and 8) that a minimum value of $\mathrm{S}$ can be clearly detected in crystalline FeNi system, which hints to an averaging effect between the individual (phase dependent) summation of $\mathrm{S}$ representing the $\mathrm{S}$ values arising from the individual phases. Consequently, the $\mathrm{S}$ in a two-phase 


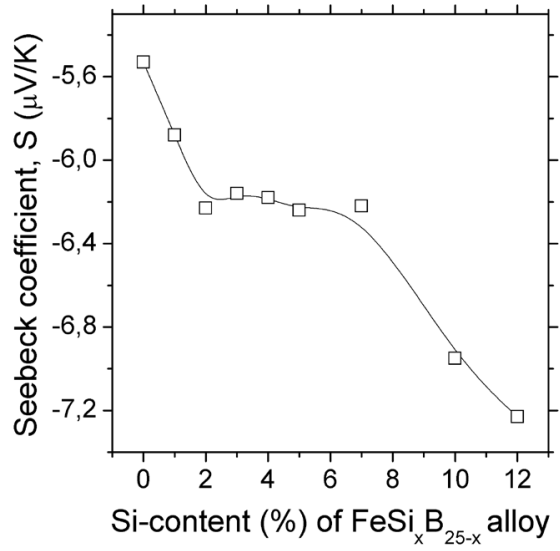

Fig. 10 The dependence of $\mathrm{S}$ on the $\mathrm{B} \backslash \mathrm{Si}$ ratio in $\mathrm{Fe}(\mathrm{BSi})_{25}$ metallic glasses

alloy can be interpreted as the algebraic summation of $\mathrm{S}_{\text {bcc phase }}$, $\mathrm{S}_{\text {fcc phase }}$ characteristic to the phase mixture according to the spirit of binary (crystalline) equilibrium Fe-Ni phase diagram.

The glassy phase represents extraordinary physical state from thermodynamical point of view: the glassy state is a single phase irrespectively of its composition. In spite of the thermodynamical interpretation (i.e. the single phase nature of glassy state) it is surprising, that the $\mathrm{S}$ (measured in glassy state) also exhibit minimum as the function of $\mathrm{Ni}$ content, similarly to that, found in the crystalline state, - as it is shown in the Fig. 11. This fact hints to the dominant impact of electronic structure in the evolution of $\mathrm{S}$ even in the disordered state. This is clearly manifested in the concentration dependence in the glassy Fe-Ni system.

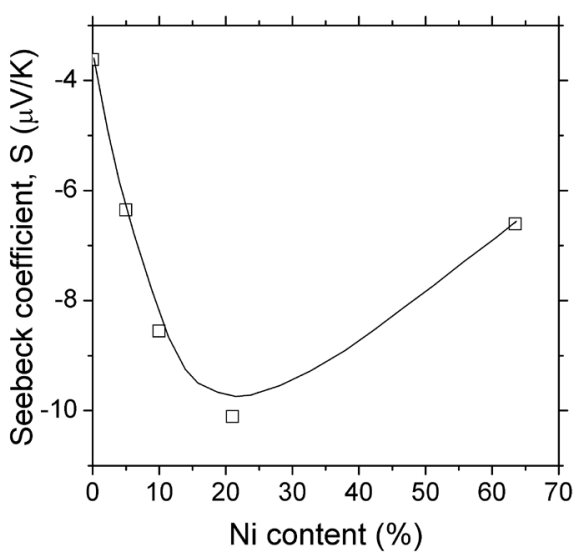

Fig. 11 The Seebeck coefficient in amorphous (FeNi) $B_{15}$ alloys versus the Ni content (Szabo et al., 2013)

\subsection{The role of phase transformation in the evolution of $\mathrm{S}$ in Fe-based glassy alloys}

The amorphous-crystalline transformation is especially favourable for studying the shift of S during phase transformation. The study of this shift is simple, when the initial state is a homogeneous (amorphous) single phase, which decompose into two crystalline phases in which both the concentration and the crystal structure is known. To demonstrate this situation, simplest composition of binary Fe-B glasses were isothermally heat treated at various temperatures, for obtaining crystalline $\alpha-\mathrm{Fe}$ and $\mathrm{Fe}_{3} \mathrm{~B}$ intermetallic compound phases.

In the Figs. 12 and 13 the $\mathrm{S}$ dependence are illustrated for the as quenched as well as for the heat treated (crystallized) $\mathrm{FeB}_{14}$ and $\mathrm{FeB}_{16} \mathrm{~s}$ samples. Due to the heat treatment at $420{ }^{\circ} \mathrm{C}$, the $\mathrm{S}$ Seebeck coefficient decreases showing the stabililzation of the structure, and components redistribution due to the crystallization, via the formation of $\alpha-\mathrm{Fe}$ and $\mathrm{Fe}_{3} \mathrm{~B}$ phases, from the originally chemically homogeneous $\mathrm{FeB}_{14}$ glass.

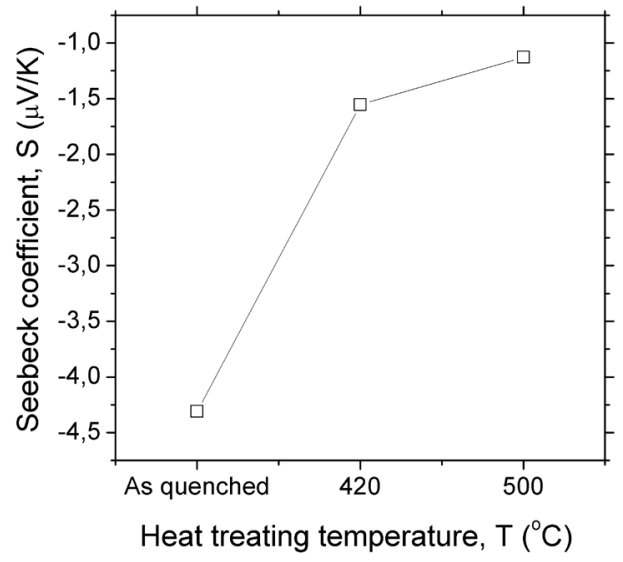

Fig. 12 The $\mathrm{S}$ versus the applied $\Delta \mathrm{T}$ in $\mathrm{FeB}_{14}$ after various crystallization heat treatments

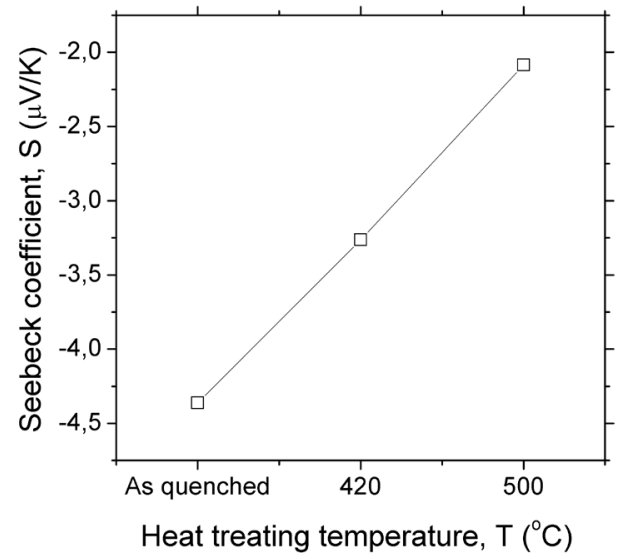

Fig. 13 The $\mathrm{S}$ versus the applied $\Delta \mathrm{T}$ in $\mathrm{FeB}_{16}$ after various crystallization heat treatments, resulting various degree of crystallization

Heat treatment at higher temperature $\left(500{ }^{\circ} \mathrm{C}\right)$ results only small additional change in the $\mathrm{S}$, indicating the nearly complete crystallization at $420^{\circ} \mathrm{C}$.

In contrast, the crystallization is not completed in $\mathrm{FeB}_{16}$ glass at $420^{\circ} \mathrm{C}$, a drop in Seebeck coefficient can be observed applying an additional heat treating temperature increase (heat treatment at $500{ }^{\circ} \mathrm{C}$ ) indicating the continuing am-cryst transformation (further thermodynamic stabilization). 


\section{Conclusion}

The focus of the work is the deeper understanding of the effect of the change in the electronic structure on the wetting angle and transport properties. It was found, that:

1. Macroscopic change of $\mathrm{S}$ and $\theta$ are experienced within the solubility limit (in the $\alpha$-phase of $\operatorname{Ag}(\mathrm{Sn}, \mathrm{Sb})$ as well as in $\mathrm{Fe}(\mathrm{Ni})_{\text {bcc }}$ alloys.

It is also supported by the concentration dependence of heat of formation, indicating the increasing cohesion in the melt drop.

2. Decreasing slope of S curves reflect to the gradual thermodynamic stabilization during the amorphous-crystalline transformation.

\section{Acknowledgement}

The project presented in this article is supported by the project EFOP-3.6.2-16-2017-00016 (Autonóm járművek dinamikája és irányítása az automatizált közlekedési rendszerek követeményeinek szinergiájában).

This work is also supported by the project, funded by the National Research, Development and Innovation (NKFIH) (Project title is: "Developing a new generation of customized medical implants and medical aids for additive technologies". The application ID number: NVKP_16-1-2016-0022.

\section{References}

Gulyás, Cs., Lovas, A. (2004). Heat Treatment Induced Mechanical and Electrical Property Changes in $\mathrm{Fe}_{40} \mathrm{Ni}_{40} \mathrm{~B}_{14} \mathrm{Si}_{6}$ Glassy Alloys Used as Seasonal Heating Elements in Transportation Engineering. Periodica Polytechnica Transportation Engineering. 32(1-2), pp. 91-112.

Ho, C. Y., Ackerman, M. W., Wu, K. Y., Havill, T. N., Bogaard, R. H., Matula, R. A., Oh, S. G., James, H. M. (1983). Electrical Resistivity of Ten Selected Binary Alloy Systems. Journal of Physical and Chemical Reference Data. 12(2), pp. 183-322. https://doi.org/10.1063/1.555684

Hlinka, J., Weltsch, Z. (2013). Wetting Ability of Silver-Gold (Ag-Au) Alloys on Graphite Substrate. In: 30th International Colloquium on Advanced Manufacturing and Repair Technologies in Vehicle Industry, Visegrád, Hungary, May 22-24, 2013. pp. 13-16.

Hultgren, R. R., Desai, P. D., Gleiser, M., Hawkins, D. T. (1973). Selected values of the thermodynamic properties of binary alloys. American Society for Testing and Materials, Metals Park, $\mathrm{OH}$.

Kaptay, G. (2005). Modelling Interfacial Energies in Metallic Systems. Material Science Forum. 473-474, pp. 1-10. https://doi.org/10.4028/www.scientific.net/MSF.473-474.1

Lovas, A., Kiss, L. F., Sommer, F. (1995). Hardness and thermal stability of Fe-Cr-metalloid glasses. Journal of Non-Crystalline Solids. 192-193, pp. 608-611. https://doi.org/10.1016/0022-3093(95)00415-7

Mott, N. (1993). Conduction in Non-Crystalline Materials. 2nd ed., Clarendon Press, Wotton-under-Edge, UK.

Salacz, I., Weltsch, Z. (2013). Alloying Effects on Wetting Ability of Diluted $\mathrm{Cu}-\mathrm{Sn}$ Melts on Graphite Substrates. In: 30th International Colloquium on Advanced Manufacturing and Repair Technologies in Vehicle Industry, Visegrád, Hungary, May 22-24, 2013. pp. 25-28.
Swartzendruber, L. J., Itkin, V. P., Alcock, C. B. (1991). The Fe-Ni (iron-nickel) system. Journal of Phase Equilibria. 12(3), pp. 288-312. https://doi.org/10.1007/BF02649918

Szabó, A., Bán, K., Juhász, G., Novak, L., Lovas, A. (2012). A complex sudy of surface fatigue in carbon steels caused by rolling contact and sliding friction. In: Proceedings of 18th International Conference on Applied Physics of Condensed Matter. Strbske Pleso, Slovakia, Jun. 20-22, 2012, p. 46.

Szabo, A., Lovas, A. (2009). Some observation and considerations for the thermopower measurements used as non-destructive material testing. Journal of Machine Manufacturing. (Special Triple Edition) 49(E3-E5), pp. 31-34.

Szabo, A., Varga, K., Lovas, A. (2013). Thermopower Measurements in Selected, Fe-based Alloys of Crystalline and Glassy Structure. In: 30th International Colloquium on Advanced Manufacturing and Repair Technologies in Vehicle Industry, Visegrád, Hungary, May 22-24, 2013. pp. 29-34.

Weltsch, Z., Tichy, G., Vandrus, Z., Lovas, A. (2011). Bulk Electron Concentration and the Surface Tension of Liquid Ag-Based Solutions. Perner's Contacts. 6(2), (Special Issue), pp. 221-227. 